\title{
ALIENAÇÃO PARENTAL
}

Barbara Maria de Oliveira Vilella, Thainá Arcanjo da C. Silva

Universidade do Oeste Paulista, Curso de Direito, Presidente Prudente, SP. E-mail: tatyarcanjo1@gmail.com

\section{RESUMO}

O presente artigo tem por objetivo analisar a alienação parental, como um todo, desde sua formação, à ocorrência e as consequências geradas pela sua prática. Apesar de ser um tema recente na pauta de discussão brasileira social e jurídica, regulamentada pela Lei no 12.318/2010, já é algo que ocorre a anos, o que o torna um assunto tão polêmico e complexo, pois envolve questões sociais e familiares, dentre elas a separação não amigável dos genitores, afetando principalmente o menor, de certa forma, indefeso, causando-lhe prejuízos físicos e mentais, como abordados posteriormente. Constata-se neste estudo, também, casos concretos jurisprudenciais e conceitos bibliográficos.

Palavras-chave: Alienação, Menor, Complexo, Consequência, Família.

\section{PARENTAL ALIENATION}

\begin{abstract}
This present article aims to analyze a parental alienation, as a whole, from its formation, to the occurrence and as consequences generated by its practice. Although it is a recent topic in the Brazilian social and legal discussion agenda, regulated by the law $12.318 / 2010$, it is already something that occurs for years, which makes it such a controversial and complex subject, because it involves social and family, among them the unfriendly divorce between the genitors, issues that mainly affect the lesser, in a sense, helpless, causing him physical and mental damages, as covered in this study. It is also verified in this article, concrete jurisprudence cases and bibliographic concepts.
\end{abstract}

Keywords: Alienation, Minor, Complex, Consequence, Family. 


\section{INTRODUÇÃO}

Muito se tem discutido acerca da Lei no 12.318/2010, referente a Alienação Parental, que é comum nos dias atuais, tornando-se um assunto a ser discutido com mais frequência. Não é de hoje que este problema atinge os menores, derivados do fim de relacionamento entre os seus genitores, que na busca de desmerecer o outro utiliza de meios de alienação em seu favor.

Destaca-se nesse artigo, assunto relevante sobre a situação dos menores, que são diretamente atingidos com as mudanças decorrentes da separação fazendo com que a partir deste ponto inicia-se uma disputa e controle sobre as decisões da vida do menor atingindo não somente o físico, como o mental deste.

Dentro deste tema específico, busca-se demonstrar a importância e o cuidado necessário nos quais os genitores precisam ter em relação ao menor, pois é evidente que as consequências de tais atos práticos refletem na área jurídica.

O objetivo deste estudo foi abordar este tema mais afundo e os possíveis problemas decorrentes da alienação que poderão sofrer os menores.

\section{METODOLOGIA}

Para o desenvolvimento deste trabalho se fez necessário examinar a Lei 12.318/2010 sancionada pelo Ex-Presidente Luiz Inácio Lula da Silva, que dispõe sobre a alienação parental. A Síndrome da alienação parental - SAP, foi proposta e estudada pelo psiquiatra norte-americano Richard Gardner nos anos 80, após isso, diversos estudos a sucederam, e a referida lei foi criada e promulgada.

Versa nesta norma jurídica exemplos de formas em que esta ação pode ser praticada e identificada, e caracteriza tal ocorrência como algo prejudicial ao direito fundamental da criança e do adolescente de convivência familiar saudável.

Aborda também as medidas a serem tomadas pelo juiz, desde o trâmite após a constatação da ocorrência, até as penalidades disponíveis para aplicação.

\section{RESULTADOS}

Com relação ao tema arguido acima, expõe-se agora duas jurisprudências a fim de comprovar o estudo feito acerca do tema, no que tange a ocorrência da alienação parental, e como é tratada pelo judiciário.

APELAÇÃo CÍvel. AÇÃo DE GUARDA. PEDIDO INCIDENTE DE ALIENAÇÃO PARENTAL CONFIGURADA. A guarda é instituto que visa à proteção dos interesses dos menores. $O$ seu bem-estar deve se sobrepor, como um valor maior, a quaisquer interesses outros, sejam dos genitores ou de terceiros. Na hipótese, a forma como procedeu o genitor, em completo desrespeito à própria filha, impedindo o convívio da filha com a mãe, e plantando falsas memórias contra a genitora, dão conta da alienação parental praticada pelo genitor. APELO DESPROVIDO. (Apelação Cível №70076918309, Sétima Câmara Cível, Tribunal de Justiça do RS, Relator: Liselena Schifino Robles Ribeiro, Julgado em 25/04/2018).

ALTERAÇÃO DE GUARDA. FILHA MENOR. INDÍCIOS DE ALIENAÇÃO PARENTAL. 1. Deve sempre prevalecer o interesse da criança ou adolescente, acima de todos os demais. 2. Não estando a adolescente em situação de risco e mantendo ela boa convivência com a genitora, com quem sempre conviveu, descabe promover a alteração de guarda. 3 . Necessitando a genitora superar seus conflitos pessoais e evitar conduta que configure alienação parental, deverá iniciar de forma imediata o acompanhamento psicológico e a terapia familiar. Recurso desprovido. (Apelação Cível №70062004692, Sétima Câmara Cível, Tribunal de Justiça do RS, Relator: Sérgio Fernando de Vasconcellos Chaves, Julgado em 26/11/2014). 
Mediante análise das jurisprudências, observa-se a cautela do legislador ao preservar o direito, interesse e bem-estar do menor, garantindo assim que o mesmo não fique em situação de risco, e consiga conviver com seus genitores tranquilamente.

\section{DISCUSSÃO}

Todos sabem que, em nosso país, há tempos, observa-se o comportamento de casais após a separação envolvendo filhos menores, que em uma tentativa de punir o antes par, e refletindo a indignação sentida neste procedimento, castiga o outro genitor com o intuito de ampliar o abismo entre pais e filhos.

Devido a isso, entende-se por alienação parental uma conduta exercida pelos genitores, avós ou até mesmo parceiros dos genitores com o objetivo de induzir, manipular uma criança ou adolescente, interferindo assim em sua formação psicológica. Estes atos são praticados usualmente para que estes responsáveis obtenham a guarda ou vigilância do menor; e para criar dificuldades no convívio familiar.

Atendido pela Lei $12.318 / 2010$, o assunto requer extrema atenção, pois sua frequência aumenta exponencialmente na sociedade hodierna, no entanto não é de benefício ou boa saúde de nenhuma das partes envolvidas no mesmo.

Gardner (2002) propõe oito sintomas para se observar e identificar, e caso a maioria seja apresentado, deverá ser caracterizado como uma "síndrome", conceituando como

um distúrbio da infância que aparece quase exclusivamente no contexto de disputas de custódia de crianças. Sua manifestação preliminar é a campanha denegritória contra um dos genitores, uma campanha feita pela própria criança e que não tenha nenhuma justificação. Resulta da combinação das instruções de um genitor (o que faz a "lavagem cerebral, programação, doutrinação") e contribuições da própria criança para caluniar o genitor-alvo. Quando o abuso e/ou a negligência parentais verdadeiros estão presentes, a animosidade da criança pode ser justificada, e assim a explicação de Síndrome de Alienação Parental para a hostilidade da criança não é aplicável. (GARDNER, 2002).

$\mathrm{Na}$ referida lei, existe um rol exemplificativo de ações que caracterizam a alienação parental, dentre elas o impedimento de visita nos dias designados pelo juiz; depreciar o outro durante a visitação do menor; ameaças de abandono caso a criança goste do outro e de sua companhia; ou até mesmo caluniar o genitor ou seus familiares a fim de dificultar a convivência deles com a criança ou adolescente.

Isto posto, os realmente prejudicados com a situação são as crianças, sofrendo assim física e mentalmente, podendo isto ser demonstrado através de distúrbios alimentares, timidez excessiva e a indecisão exacerbada. Com isso, o filho pode sofrer com a perda da capacidade crítica de avaliar os aspectos bons e ruins da relação, acabando por assim criar uma imagem diferente da realidade do convívio com seus genitores.

Importante ressaltar que o genitor que pratica atos da alienação parental compromete a convivência familiar, violando além do artigo 3ㅇ da Lei 12.318/2010, como também o artigo 19 do ECA e 227 da Constituição Federal, que em um todo protegem e zelam a convivência familiar.

Obtém-se como exemplo desta conduta a história de Sean Goldman, menino que por anos foi alvo de uma disputa judicial pela sua guarda com as famílias maternal brasileira e paternal estadunidense. Nos dias atuais, já com 18 anos, Sean confessa ter sido vítima de mentiras contadas por sua avó materna, pois a mesma não queria que o neto permanecesse nos Estados Unidos.

Caso essa prática seja cometida, o juiz mandará realizar um estudo psicossocial ou biopsicossocial das pessoas envolvidas e de suas famílias, cujo laudo deverá ser entregue, no prazo máximo de 90 (noventa) dias. Poderá ainda, caso constatada a prática, aplicar uma medida protetiva e seu descumprimento pode levar o infrator a sofrer a inversão da guarda previamente 
estabelecida e a suspensão da autoridade parental. E a criança deverá passar por acompanhamento psicoterápico.

O artigo 60 da Lei de Alienação Parental prevê um rol no qual o juiz ex officio constando os atos típicos da alienação poderá determinar, sem influência no processo de âmbito civil ou penal, a aplicação de sanções (cumulativas ou não) ao alienador.

Para que isso ocorra, a alienação deverá ser arguida a qualquer tempo, no entanto, devidamente comprovada, não por meio de achismo, por tratar-se de alegação muito grave. Um dos meios utilizados para apoiar o caso, é o chamado depoimento especial. Esta forma de prova é o relato da criança ou do adolescente à Justiça ou aos integrantes do Sistema Judiciário. É considerada uma forma diferenciada de escuta.

Atualmente, os menores, vítimas desse abuso, são ouvidos, por cerca de oito vezes, durante o procedimento de investigação e da ação judicial. Depoimentos estes que são filmados e anexados ao processo, para fim de consulta e prova judicial.

Encontra-se possível solução pelo legislador através da adoção da guarda compartilhada, no entanto a mesma deve ser efetiva, e não somente no papel.

\section{CONCLUSÃO}

Mediante o exposto, objetiva-se que o assunto deve ser tratado como prioridade quando constatado, e sua lei, no 12.318/2010, aplicada rigorosamente, com o intuito de preservar os direitos fundamentais do menor envolvido, como o de ter uma convivência familiar saudável.

Em virtude dos fatos mencionados, é-se levado a acreditar que o legislador ao criar a lei, levou em consideração a proteção da criança e/ou adolescente, restando por fim a criação de um apoio psicológico para os genitores e envolvidos, como medidas para evitar sua ocorrência.

\section{REFERÊNCIAS}

BRASIL. Lei №12.318/2010. Brasília, DF. Planalto, 2010.

BRASIL. Constituição da República Federativa do Brasil. Brasília, DF. Planalto, 1988.

BRASIL. Lei no8.069/1990. Brasília, DF. Planalto, 1990.

Comentários à lei de alienação parental: Lei nำ12.318/10. Disponível em: <https://jus.com.br/artigos/17871/comentarios-a-lei-de-alienacao-parental-lei-n-12-318-10>. Acesso em agosto de 2018.

Lei de Alienação Parental comentada. Disponível em: <https://www.direitocom.com/lei-de-alienacao-parental-comentada>.

Acesso em Agosto de 2018.

FIGUEIREDO, Fábio Vieira. Alienação Parental: aspectos materiais e processuais da Lei n. 12.318 de 25-8-2010. São Paulo: Saraiva, 2011.

GARDNER, R. Differentiating between parental alienation syndrome and bona fide abuse-neglect. American Jounal of Family Therapy. April 1999. Tradução para o português por Rita Rafaeli, 2002. Disponível em: <http://www.scribd.com/doc/6155591/Sindrome-da-Alienacao-Parental-RichardGardner>. Acesso em julho de 2018.

GROENINGA, G. O Fenômeno alienação parental. Direito de família. Coord. Rolf Madaleno e Rodrigo da Cunha Pereira. Rio de Janeiro: Forense, 2008. 
JUNIOR, Antônio Veloso Peleja. Síndrome de alienação parental - Aspectos Materiais e processuais. Jus navegandi, Teresina, 2010. <http://jus.com.br/artigos/18089>. Acesso em julho de 2018.

JURISPRUDÊNCIA. TJ-RS - AC: 70076918309 RS, Relator: Liselena Schifino Robles Ribeiro, Data de Julgamento: 25/04/2018, Sétima Câmara Cível, Data de Publicação: Diário da Justiça do dia 27/04/2018.

JURISPRUDÊNCIA. TJ-RS - AC: 70062004692 RS, Relator: Sérgio Fernando de Vasconcellos Chaves, Data de Julgamento: 26/11/2014, Sétima Câmara Cível, Data de Publicação: Diário da Justiça do dia 01/12/2014).

PINHO, Marco Antônio Garcia de. Nova Lei 12.318/10 - Alienação Parental. Disponível em: <www.jurisway.org.br/v2/dhall.asp?id_dh=3329>. Acesso em julho de 2018.

Resolução n08/2010 e $\mathrm{n} 007 / 2003$. Conselho Federal de Psicologia. Disponível em: $<$ www.pol.org.br>. Acesso em julho de 2018. 